\title{
Zoonotic gastrointestinal parasite burden of local dogs in Zaria, Northern Nigeria: Implications for human health
}

\author{
Christopher I. Ogbaje ${ }^{1}$, Raphael A. Ofukwu², and Ikwe A. Ajogi ${ }^{3}$
}

1. Department of Veterinary Parasitology and Entomology, College of Veterinary Medicine, University of Agriculture, Makurdi, Nigeria; 2. Department of Veterinary Public Health and Preventive Medicine, College of Veterinary Medicine, University of Agriculture, Makurdi, Nigeria; 3. Department of Veterinary Public Health and Preventive Medicine, Faculty of Veterinary Medicine, Ahmadu Bello University, Zaria, Nigeria.

Corresponding author: Christopher I. Ogbaje, e-mail: igochechriso@yahoo.co.uk, RAO: ofukwu@hotmail.com, IAA: ajogi@yahoo.com

Received: 15-07-2015, Revised: 18-09-2015, Accepted: 30-09-2015, Published online: 25-10-2015

How to cite this article: Ogbaje CI, Ofukwu RA, Ajogi IA. Zoonotic gastrointestinal parasite burden of local dogs in Zaria, Northern Nigeria: Implications for human health. Int J One Health 2015;1:32-36.

\begin{abstract}
Background: Zoonotic gastrointestinal parasites of dogs are of the global problem particularly in the developing countries. Dogs are the most common pet animals worldwide and have been reported to be hosts of many intestinal parasites of zoonotic importance globally. In Nigeria, gastrointestinal helminthes of dogs is currently endemic in 20 of the 36 states.

Aim: In general, dogs are the closest animals to humans and for that reason we decided to carry out a survey study to check the incidence of these parasites in dogs and to ascertain the level of environmental contamination in the study area.

Materials and Methods: Fecal samples were collected from dog patients presented to small animal clinic of Veterinary Teaching Hospital of Faculty of Veterinary Medicine, Ahmadu Bello University Zaria, dog's fecal droppings from the streets, and residential Quarters of the University and gastrointestinal tracts (GIT) of dogs from dogs slaughtering house at Basawa Barrack, Zaria. Three methods were used in the analysis of the samples; simple flotation, sedimentation, and GIT processing methods within $48 \mathrm{~h}$ of collection.
\end{abstract}

Results: Out of 224 samples analyzed $76(33.9 \%)$ were positive of at least one of the parasites. Of the 101 samples from streets and residential quarters of ABU, Zaria, Isospora spp. 12(11.9\%) recorded the highest prevalence rate followed by Taenia spp. 6(5.9\%), then Toxocara canis, Ancylostoma caninum, and Dipylidium caninum were 5.0\%, 4.0\%, and 1.0\%, respectively. Isospora spp. (19.0\%) recorded the highest prevalence rate for the 100 samples collected from small animal clinic. Other parasites encountered were T. canis (8.0\%), A. caninum (8.0\%) and Taenia spp. (5.0\%). Parasites observed from the 23 gastrointestinal contents from "dog slaughtered houses" were T. canis (17.3\%), Isospora spp.(13.1\%) and A. caninum (4.3).

Conclusion: The study revealed that zoonotic gastrointestinal parasites of dogs are endemic in Zaria and the general public in the area are at high risk of being infected with these parasites.However, there are no statistically significant differences in the level of zoonotic parasitic infestation in the three sample sites at $\mathrm{p}<0.05$.

Keywords: dog, gastrointestinal, helminthes, parasite, zoonosis

\section{Introduction}

Zoonotic diseases can be caused by viruses, bacteria, parasites, and fungi. Some of these diseases are very common. The symptoms and signs of parasitic zoonosis are dependent on the parasite and the person involved. In Nigeria, gastrointestinal helminthes of dogs is currently endemic in 20 of the 36 states [1].

Dogs are the most common pet animals worldwide, and it have been reported that they are hosts of many intestinal parasites of zoonotic importance globally $[2,3]$. These parasites are usually transmitted to humans through direct contact with infected pets or exposure to environments contaminated with infected animal's feces [4]. Children are at the highest risk of the zoonotic infection because of their closeness to pets and playing with contaminated soil [5]. The importance

Copyright: The authors. This article is an open access article licensed under the terms of the Creative Commons Attributin License (http:// creative commons.org/licenses/by/2.0) which permits unrestricted use, distribution and reproduction in any medium, provided the work is properly cited. of dogs to their owners cannot be overemphasize as it has contributed greatly to the owners social and emotional well-being [6]. Apart from being used as a pet, dogs are also used for hunting, security, breeding and sport $[7,8]$. Some of the potential zoonotic gastrointestinal parasites of dogs include roundworms and hookworms whose infective stages may contaminate and persist in an environment for a long period of time [9]. The Larvae hatch out of the eggs and can infect human in two different ways. A person can ingest the larvae through contaminated food and water or when putting unwashed hands in their mouth. Alternatively, the larvae can penetrate directly through the skin. The most common zoonotic diseases of important in the developing countries are cutaneous and visceral larva migrans, hydatidosis, and tunniasis [10].

In Nigeria, occurrences of these zoonotic parasitic infections have been reported widely in dogs with differences in prevalence depending on the geographical location [11-14]. Although a lot have been done on the environmental contamination of the eggs 
of parasites of zoonotic important, but little has been done on direct evaluation of dogs feces on streets and residential areas to ascertain the possible risk posted to the inhabitants of the areas.

This study was designed and conducted to check whether dogs feces on streets and residential areas post any risk to the public and to update practicing veterinarians the happening in their environment whose will in turn advise dog owners on how to minimize the risk of zoonotic transmission.

\section{Materials and Methods}

\section{Ethical approval}

All samples were collected as per standard sample collection procedure without harming the animals.

\section{Study Area}

The study was conducted in Zaria, a University town that is located between Latitude $9^{\circ} 08^{\prime}$ and $11^{\circ} 07^{\prime} \mathrm{N}$ and longitude $6^{\circ} 10^{\prime}$ and $8^{\circ} 48^{\prime} \mathrm{E}$ with an annual rainfall of about $1016 \mathrm{~mm}$ and temperature range of $41-27^{\circ} \mathrm{C}$ [15]. It lies within the Sudan Savannah Vegetation Zone of Nigeria with distinct wet (April-November) and dry (December-March) Seasons. The settlements of the area are mainly public and civil servants with few traders.

\section{Animal for the study}

Dogs were used for the study. Dogs fecal samples were collected from the staff residential quarters, small animal clinic of the Faculty of Veterinary Medicine, Ahmadu Bello University (ABU), Zaria, Samaru village, and gastrointestinal tract (GIT) of dogs slaughtered for food at "dogs slaughtering houses." Most of the dogs seen in the study area (Sabon Gari Local Government area) are semi-stray (i.e. their movements are not restricted by the owners). They are mainly Nigerian local breeds (Mongrels). There are few "dog slaughtering houses" for human consumption in Sabon Gari Local Government Area, mostly around the two Military barracks located in the area (i.e. Depot and Basawa Barracks).

\section{Sample collection}

Three sampling sites were used; ABU, Zaria staff quarters and the adjourning areas, Small Animal Clinic of the Faculty of Veterinary Medicine, ABU, Zaria, and the Dog meat Market at the Basawa Military Baracks, Zaria were selected. Each site was visited once a week for 24 weeks (6 Months; January-June) for the sample collection.

\section{Fecal samples of dogs from residential areas}

For the residential areas, household dogs in homes that were randomly selected were restrained and identified thereafter 5-10g of feces from each was scooped into a sterile white polyethylene bags using the finger of gloved hand and the fore-finger was inserted into the animal's rectum, while the other hand was used to support the caudoventral abdominal area of the animal and fecal materials were scooped from the rectum.
Fecal samples from identified dogs were similarly obtained from patient presented to the small animal clinic for treatment and/or vaccination. Dog's fecal samples were also collected from the compounds and streets of dog owners. These samples were transported in a cold ice pack to Department of Veterinary Parasitology Laboratory of the Faculty and analyzed for eggs or Helminth identification according to Soulsby [16].

\section{Samples of GIT of dogs}

GIT of dogs slaughtered for human consumption at the Basawa Military Barracks "Mommy" Market were randomly collected immediately after slaughtered. Each GITwas ligated at the gastro-esophageal and recto-anal junctions and then transported in ice packed cooler to the Parasitology Laboratory for analysis. Samples not analyzed immediately were stored in the freezer at $-4^{\circ} \mathrm{C}$.

\section{Laboratory analysis of samples}

Each fecal sample was processed using the flotation and sedimentation methods as described earlier while the gastrointestinal content was processed for helminthes using a modification of the method described by Joneset al. [17].

\section{Flotation method}

About $2 \mathrm{~g}$ of the fecal sample was placed in polyethylene tube, and flotation medium was added to the sample in the tube. The sample was then broken and properly mixed with the flotation fluid. The mixture was filtered into a centrifuge tube, and the filtrate was topped to fill the centrifuge tube. A cover slip was placed on the filled tube and left to stand for 3-5 min. The cover slip was later transferred onto a glass slide and view under microscope for identification of any parasite eggs in the sample, mostly cestodes and nematodes eggs.

\section{Processing of the gastrointestinal contents}

The stomach and intestinal tract were opened along their entire length and the contents, including mucosa linings were scrapped into a plastic bucket filled with clean tap water.

The content was then stirred carefully and the suspension poured through wire mesh sieve into another plastic bucket. The unsieved content, fecal particle and large intestinal worms were stored away for examination and receiving while the filtrate was allowed to settle for $3 \mathrm{~h}$. The resulting supernatant due to filtration was gently decanted and the sediments transferred to shallow glass petri-dishes. These were examined for the presence of worms or segments that pass through the sieve on a viewing board using a magnifying glass.

\section{Sedimentation method}

For each of the gastrointestinal sample collected, $4 \mathrm{~g}$ was dissolved in tap water and mixed thoroughly. The suspension was then filtered through a wire mesh sieve and allowed to settle for one hour. The resulting supernatant was gently decanted and the sediments 
transferred to shallow glass petri dishes and examined for the presence of helminthes or segments of it. Thereafter, 1-2 drop(s) of the sediment was placed on a glass slide in triplicate and a drop of iodine solution added and covered with cover slip. These were viewed under the microscope $(\times 10)$ for the presence of any helminthes eggs.

\section{Statistical analysis}

The data generated from the study were analyzed using Graph Pad Prism (GPP) 2015 software Inc. The differences in the level of zoonotic parasitic infestations in the three sample sites were compared. Significant level was determined at $\mathrm{p}<0.05$ for all the statistical results.

\section{Results}

A total prevalence rate of $33.9 \%$ was obtained from all the samples examined from the three sampled areas, (i.e. 76 samples were positive of at least single infection out of 224 samples examined). Of the total of 101 samples from fecal dropping on the streets and residential areas examined; Isospora spp. accounted for 12(11.9\%); Taenia spp. 6(5.9\%), Toxocara canis 5(5.0\%), Ancylosoma caninum 4(4.0\%), and Dipylidium caninum 1(1.0\%).

A total of 100 fecal samples from dog patients presented at Small Animal Clinic were analyzed; of these, Isospora species had the highest prevalence of $19(19 \%)$, T. canis $8(8.0 \%)$, A. caninum $8(8.0 \%)$ and Taenia species had the least prevalence 5(5.0\%).

A total of 23 gastrointestinal contents of dogs were examined. Gastrointestinal parasite eggs of dogs found were; $T$. canis $4(17.4 \%)$, Isospora species $3(13.1 \%)$ and $A$. caninum $1(4.3 \%)$. The results are presented in the charts below (Table-1 and Figure-1).

\section{Discussion}

The overall prevalence rate of $33.9 \%$ recorded in this study is relatively low compare to what was reported from other parts of Nigeria; from Ilorin (68\%), Enugu (68.5\%), Zuru, Kebbi (78.85\%), and Makurdi (36.7\%). However, [18], (24\%), from Ibadan reported a lower value than what was obtained in this study. The prevalence rate recorded in this study is far lower than what was reported from other parts of the world; [19] from Spain (71\%), [20], from Mexico (85\%), [21] from South Africa (76\%) and [22], from
Morocco $(100 \%)$. The low prevalence rate observed in this study may be attributed to the readily available Veterinary services and the increased awareness of zoonotic parasites associated with dogs in Zaria which may not be so in other geographical areas earlier mentioned.

This study has shown that the prevalence rate of Isospora spp., Toxocara spp. and Ancylostoma spp. are highest in dog patients presented to small animal clinic of Veterinary Teaching Hospital, A. B. U, Zaria, whereas Taenia spp. are highest in dog fecal samples collected along streets and residential areas. Toxocara spp. $(17.3 \%)$ had the highest prevalence in gastrointestinal content of dogs prepared for human consumption. However, the differences in the level of parasitic infestations in the three sample sites were not statistically significant at $\mathrm{p}<0.05$.

All these parasites are of zoonotic importance. The high prevalence rate of Toxocara spp. obtained in this study is comparable to $19.4 \%$ obtained by [23]. Taenia spp. have eggs that are similar to Echinococcus

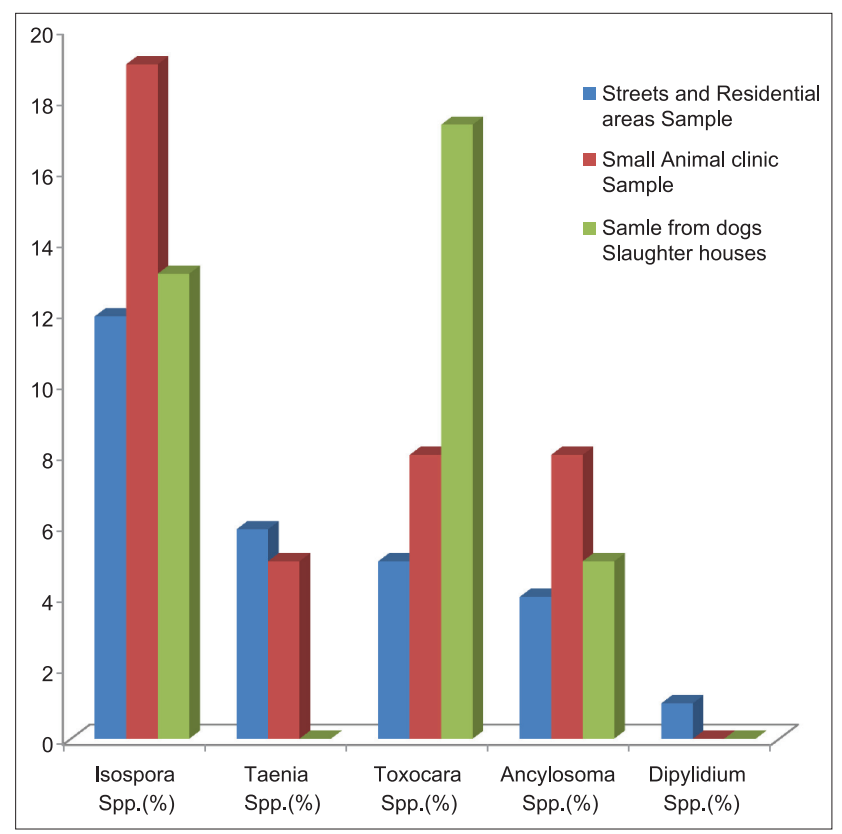

Figure-1: Prevalence of zoonotic gastrointestinal parasites of dogs from dog's fecal samples of dogs from streets and residential premises of Ahmadu Bello University Quarters [-], small animal clinic of Veterinary Teaching Hospital, Faculty of Veterinary Faculty, Ahmadu Bello University, Zaria [-] and dogs slaughtering houses Zaria [-].

Table-1: Zoonotic parasites of dogs from fecal dropping along the streets of ABU Staff quarters, SAC and Mami Market (dogs slaughtering house).

\begin{tabular}{lcccc}
\hline Species & Staff quarters/streets (\%) & SAC (\%) & GIT contents (\%) & Total (\%) \\
\hline Isospora spp. & $12(11.9)$ & $19(19)$ & $3(13.1)$ & $34(15.2)$ \\
Taenia spp. & $6(5.9)$ & $5(5.0)$ & $0(0)$ & $11(4.9)$ \\
Toxocaria spp. & $5(5.0)$ & $8(8.0)$ & $4(17.3)$ & $17(7.6)$ \\
Ancylostoma caninium & $4(4.0)$ & $8(8.0)$ & $1(4.3)$ & $13(5.8)$ \\
Diplylidium caninium & $1(1.0)$ & $0(0)$ & $0(0)$ & $1(0.4)$ \\
Total positive & $28(27.7)$ & $40(40.0)$ & $8(34.8)$ & $76(33.9)$ \\
\hline
\end{tabular}

Sample size $=224$, Total positive samples $=76$, Sample size of staff/streets $=101, \mathrm{SAC}=100$, GIT=23. GIT=Gastrointestinal tracts, $\mathrm{SAC}=$ Small animal clinic, $\mathrm{ABU}=\mathrm{Ahmadu}$ Bello University 
granulosus eggs, so it was not possible to differentiate E. granulosus eggs from other Taenia eggs such as Taenia serialis, Taenia ovis, Taenia pisiformis, Taenia hydratigena and many others. It is possible that E. granulosus eggs would have been present. Surprisingly, there was no Taenia eggs found in dogs prepare for human consumption. This may be probably due to some limitations in our methodology.

Toxocara spp. and A. caninum, (8.0\%) each had the highest prevalent rates for samples collected from dogs in small animal clinic of Veterinary Teaching Hospital; this is in agreement with the finding by [24]. These two parasites are of serious zoonotic importance. T. canis causes visceral larval migrans. It is a chronic and mild disease due to migration of the larval stage in organs and tissue of man. Cutaneous larval migrans called "creeping eruption" is cause by A. caninum. The infestations are acquired through active skin penetrations or ingestion of contaminated feed and water [25].

Some species of Isospora are pathogenic to man leading to sporadic and mild infection. Dogs and cats serve as the intermediate hosts [26].

D. caninum eggs were observed only in fecal samples deposited along the streets and residential houses. Parasitic infestations are commonly associated with children because of their closeness to pet animals and eating of contaminated soil for these reasons children in this locality are at higher risk of infestation with these parasites.

\section{Conclusion}

The study shows that gastrointestinal parasites of dogs are endemic in Zaria. This implies that the general public's residing and also consuming dog meat in the environment are at high risk of infections with agents of these diseases. Aggressive public enlightment on the public health implication of environmental contamination of dogs faces and consumption of improperly cooked dog meat should be carry out and the importance of regular deworming of dogs by their owners to reduce the incidence of these parasites should be conducted by the field Veterinarians in the area.

We recommend policy that will help in elimination of stray dogs from the environment to reduce the risk of contracting these parasites.

\section{Authors' Contributions}

CIO conducted the research and actively prepared the manuscript. AIA designed the work and provided the information. AIA died during the course of the study. RAO participated in the manuscript preparation and advice during the work. CIO and RAO read and approved the final manuscript.

\section{Acknowledgments}

The authors acknowledge Mr. Daniel Gimba, Yunusa, Joseph Damsa and M. Odoba for their technical support. The research was self-funded. The authors provided all the materials and fund for the work.

\section{Competing Interests}

The authors declare that they have no competing interests.

\section{References}

1. Uwemedimo E, Akinola O, Dimitrios-Alexios $\mathrm{KV}$, Eniola A, Franca O,Sunday I, et al. Bayesian geostatistical model-based estimates of geospatial distribution of soil transmittedhelminthiasis and albendazole treatment requirements in Nigeria. $13^{\text {th }}$ International Congress of Parasitology 2014. August $10^{\text {th }}-15^{\text {th }}, 2014$, Mexico.

2. Schantz PM. Zoonotic parasitic infections contracted from dogs and cats: How frequent are they? 2007. http://www. capcvet.org. Accessed on 03-07-2015.

3. Satyal RC, Manandhar S, Dhakal S, Pandeya YR, Mahato BR, Chaulagain S, et al. Prevalence of gastrointestinal zoonotic helminthes in dogs of Kathmandu, Nepal. Int J Infect Microbiol 2013;2:91-4.

4. Degefu H, Tefera A, Yohannes M. Zoonotic helminth parasites in faecal samples of household dogs in Jimma town, Ethiopia. J PublicHealth Epidemiol 2011;3:138-43.

5. Karrar ZA, Rahim FA. Prevalence and risk factors of parasitic infections among under-five Sudanese children: A community based study. East Afr Med J 1995;72:103-9.

6. Robertson ID, Irwin PJ, Lymbery AJ, Thompson RC. The role of companion animals in the emergence of parasitic zoonoses. Int J Parasitol 2000;30:1369-77.

7. Abere T, Bogale B, Melaku A. Gastrointestinal helminth parasites of pet and stray dogs as a potential risk for human health in Bahir Dar Town, North-Western Ethiopia. Vet World 2013;6:388-92.

8. Pirzada NH, Sahito HA, Gopang MA, Memon MR, Pirzada M, Sanjrani MI, et al. Prevalence of intestinal parasites and risk perception of zoonotic infection for humans. DynMicrobiolInfectDis 2014;1:1-7.

9. Fisher M. Toxocara cati: An underestimated zoonotic agent. Trends Parasitol 2003;19:167-70.

10. Akao N, Ohta N. Toxocariasis in Japan. Parasitol Int 2007;56:87-93

11. Magaji AA, Mohammed MN, Saulawa MA, Salihu MD. Survey of zoonotic gastrointestinal parasites of dogs (Canis familiaris) slaughtered at Zuru area, Kebbi State, Nigeria. Sci J Vet Adv 2012;1:132-6.

12. Anene BM, Nnaji TO, Chime AB. Intestinal parasitic infections of dogs in the Nsukka area of Enugu, Nigeria.Prev Vet Med 1996;27:89-94.

13. Omudu EA, Amuta EU. Parasitology and urban livestock farming in Nigeria: Prevalence of ova in faecal and soil samples and animal ectoparasites in Makurdi. J S Afr Vet Assoc 2007; 78:40-5.

14. Ugbomoiko US, Ariza L, Heukelbach J. Parasites of importance for human health in Nigerian dogs: High prevalence and limited knowledge of pet owners. BMC Vet Res 2008:4:49.

15. Ammani AL, Ja'afaru AK, Aliyu JA, Arab AI. Climate change and maize production: Empirical evidence from Kaduna State, Nigeria. JAgric Ext 2012;16:1119-9444.

16. Soulsby EJ. Helminths, Arthropods and Protozoa of Domesticated Animals. $7^{\text {th }}$ ed. London: Lea and Febiger;1982. p. 119-27.

17. Jones O, Kebede N, Kassa T, Tilahun G, Macias C. Prevalence of dog gastrointestinal parasites and risk perception of zoonotic infection by dog owners in Wondo Genet, Southern Ethiopia. J Public Health Epidemiol2011;3:550-5.

18. Sowemimo OA, Asaolu SO. Epidemiology of intestinal helminth parasites of dogs in Ibadan, Nigeria. J Helminthol 2008;82:89-93. 
19. Martínez-Moreno FJ, Hernández S, López-Cobos E, Becerra C, Acosta I, Martínez-Moreno A. Estimation of canine intestinal parasites in Córdoba (Spain) and their risk to public health. Vet Parasitol 2007;143:7-13.

20. Eguía-Aguilar P, Cruz-Reyes A, Martínez-Maya JJ. Ecological analysis and description of the intestinal helminths present in dogs in Mexico City. Vet Parasitol 2005; 127:139-46.

21. Minnaar WN, Krecek RC, Fourie LJ. Helminths in dogs from a peri-urban resource-limited community in Free State Province, South Africa. Vet Parasitol 2002;107:343-9.

22. Pandey VS, Dakkak A, Elmamoune M. Parasites of stray dogs in Rabat region, Morocco. Ann Trop Med Parasitol
1987;81:53-5.

23. Olufemi BE, Bobade PA. Prevalence of gastrointestinal helminth parasites of dogs in Ibadan, Nigeria.Niger Vet $\mathrm{J}$ 1979;23:21-5.

24. Dusai DM. Gastrointestinal helminthiasis in dogs presented to small animal clinic of veterinary teaching Hospital, Ahmadu Bello University, Zaria. Z Vet 1989;4:2.

25. Paulos D, Addis M, Fromsa A, Mekibib B. Prevalence of gastrointestinal helminthes among dogs and owners perception about zoonotic dog parasites in Hawassa Town, Ethiopia. J Public Health Epidemiol 2012;4:205-9.

26. Schwabe CW. Veterinary Medicine and Human Health. $2^{\text {nd }}$ ed.Baltimore: Williams \& Wilkins; 1961. p. 287.

$* * * * * * * *$ 